\title{
CT Color Coded Lung Images Visualizing Faint Ground Glass Opacity as Early COVID-19 Lung Finding
}

\author{
RASHA MOSTAFA MOHAMED ALI, M.D.; MAI BAHGAT IBRAHIM GHONIMY, M.D. and \\ SAFIA BADR SAYED, M.D.
}

The Department of Diagnostic and Intervention Radiology, Faculty of Medicine, Cairo University, Egypt

\begin{abstract}
Background: For early diagnosis of pulmonary abnormalities in COVID-19 patients, a CT scan of the chest is a main and straightforward diagnostic approach. A semi-quantitative approach based on both visual and colour coded images aids in the early diagnosis of COVID-19 lung abnormalities, allowing for better disease detection and infection control.

Aim of Study: The purpose of this study is to confirm the value of color-coded lung imaging in improving the detection of faint ground glass opacities, which were the only symptom in COVID-19 patients who were diagnosed early.
\end{abstract}

Patients and Methods: This cross section study included 50 patients ( 36 males, 14 females) ranging in age from 25 to 65 years (mean age of 34.2 years) who were confirmed to be infected with SARS-CoV-2 using an RT-PCR test and were referred to the Cairo University Faculty of Medicine's Radiology department for a chest CT scan.

Results: From mid-January to April 15, 2021, we studied 50 patients in Cairo, Egypt, who had positive RT-PCR tests and pulmonary manifestations. Fifty patients $(100 \%)$ had faint ground glass opacities that were detected by both visual and colour coded images, while seven patients $(14 \%)$ had only colour coded images that were confirmed by CT HU assessment.

Conclusion: The application of both visual and color coded images improve and augment the early detection of faint ground glass opacities seen in early COVID-19 affection.

Key Words: Color coded - CT imaging - Faint GGO - Early COVID-19.

\section{Introduction}

FOR patients with positive COVID-19 infection, chest CT plays a key role in early identification and follow-up [1]

Because most COVID-19 infected individuals were detected by unique CT imaging patterns, radiological exams are critical in early diagnosis and illness course assessment.

Correspondence to: Dr. Rasha Mostafa Mohamed Ali, The Department of Diagnostic and Intervention Radiology, Faculty of Medicine, Cairo University, Egypt
Because there are now no specific therapeutic medications available for the 2019 new coronavirus disease (COVID-19), it is critical to discover the disease early and segregate the infected person from the healthy community [2] .

As a common imaging approach for pneumonia detection, multislice CT of the chest is reasonably simple to perform and results in a quick diagnosis [3].

Initial RT-PCR results have a lower sensitivity for diagnosing COVID-19 infection than chest CT scans [2].

Early identification, observation, and disease evaluation are all aided by thin-slice chest CT [4]

The aim of this study is to confirm the significance of color coded lung images in the improvement ofthe detection of faint ground glass opacities that were the only manifestation in early affected COVID-19 patients.

\section{Patients and Methods}

\section{Methods:}

\section{Ethical consideration:}

All of the patients signed a written informed consent form. The findings of this study were exclusively used for scientific purposes and not for any other objectives.

\section{Ethical approval wasn't applicable}

Study design:

This prospective study comprised 50 patients (36 males, 14 females) ranging in age from 25 to 65 years (mean age of 34.2 years) who had been verified to be infected with the COVID-19 virus and were referred for a chest MSCT. All patients who wanted a chest $\mathrm{CT}$ were given one. The re- 
search was carried out in Cairo, Egypt, from midJanuary through April 2021.

\section{Inclusion criteria:}

Laboratory proven PCR positive COVID-19 patients with chest manifestation.

\section{Exclusion criteria:}

- Patient's CT showing massive consolidative patches.

- Patients with severe artifacts on CT images.

\section{Methods:}

- A complete history was taken of all enrolled patients.

- A laboratory assessment was performed on all enrolled patients (patients with positive PCR test).

- Chest computed tomography (CT) scan:

- All patients had a 16-channel MSCT (Toshiba) CT scan of their chest.

- The following were the CT acquisition parameters in detail: (Table 1).

- $120-160 \mathrm{kVp}$ tube voltage.

- Standard tube current (reference mAs, 60120).

- $1.0 \mathrm{~mm}$ slice thickness.

- 1.0-3.0mm reconstruction interval.

- A sharp reconstruction algorithm was used.

- CT scans were taken with the patient in a supine posture, full inspiration suspended, and no contrast medium.

- All photos were seen in lung (width, 1500 $\mathrm{HU}$; level, $700 \mathrm{HU}$ ) and mediastinal (width, $350 \mathrm{HU}$; level, $40 \mathrm{HU}$ ) windows.

Table (1): MSCT technique.

\begin{tabular}{ll}
\hline Tube voltage & $120 \mathrm{kVp}$ \\
\hline Tube current & $60-120 \mathrm{mAp}$ \\
Slice thickness & $1 \mathrm{~mm}$ \\
Reconstruction interval & $1 \mathrm{~mm}$ \\
Patient position & Supine \\
Respiration & Breath hold full inspiration \\
Matrix size & $512 \times 512$ \\
\hline
\end{tabular}

- 3D volume rendering lung images in VR (3 colours):

- The images were transferred to a different workstation and analysed and modified using a DICOM viewer.

- To exclude soft tissue surrounding the lung, threshold values of -500 to $-1024 \mathrm{HU}$ were used.
- Using the colour mask tool, enter the density range, and select the desired colour, this programme and Di-com viewer automatically analyses the density distribution of the lungs into different colours, indicating the area that the HU ranges occupy in the image.

- GGO was characterised as normally aerated (ranging from -750 to $-900 \mathrm{HU}$ ) and the value range of (-750 HU to $-500 \mathrm{HU})$ [5] . (Fig. 1)

- Two professional radiologist independently examined the chest CT scan, looking for faint ground glass opacities in axial lung window images as well as colour coded images.

- color coded method depends on measuring HU unit of the lesion as well as it relays on the color coded image assessment while the quantitative method is an objective method that depend only upon HU values calculation.

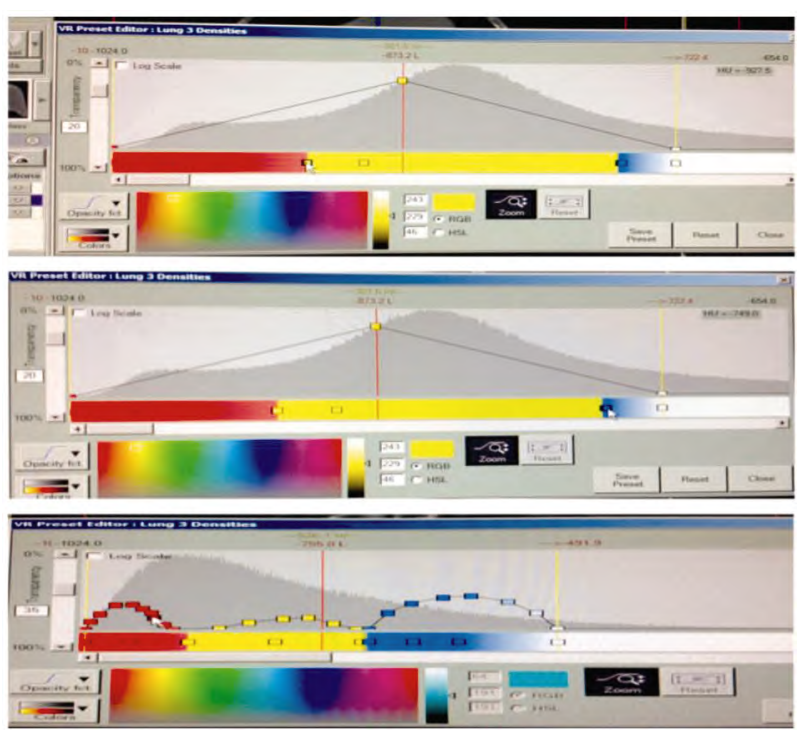

Fig. (1): Showing Vitrea work station preset, Normally aerated (vary from -750 to $-900 \mathrm{HU}$ ) and the value range of $(-750 \mathrm{HU}$ to $-500 \mathrm{HU})$ was defined as GGO.

\section{Statistical analysis:}

Owing to small sample size, findings are presented as medians and interquartile ranges.

\section{Results}

This cross-sectional investigation included 50 patients (34 males, 16 females) ranging in age from 25 to 65 years (mean age 34.2 years) who were proven to be infected with SARS-CoV-2 through RT-PCR.

In a private radiology centre in Cairo, CT of the chest was conducted on all patients using a 16channel MSCT (Toshiba) and processed in a sepa- 
rate workstation (Vitrea workstation) with a specific DICOM reader.

All of the patients had been in contact with people who were infected with COVID-19. It took around 7 days from the start of the symptoms until the first chest CT scan.

Fever was seen in 38 patients $(76 \%)$ and dry cough in 28 patients (56\%) as the first symptoms, whereas dyspnea was seen in 15 patients $(30 \%)$.

The most prevalent radiological finding was ground glass opacity, which was present in all 50 patients (100\%) and was recognised by both visual and colour coded pictures, although the GGO was very faint in 7 patients (14\%) and was only visualised by colour coded images and confirmed by $\mathrm{CT}$ density evaluation. The lesions ranged in size from 1 to $3 \mathrm{~cm}$ in diameter.

Lower zone predominance was seen in 40 individuals $(80 \%)$, equal distribution between the upper and lower zones was seen in 7 patients (14\%), and upper zone predominant changes were seen in 3 patients $(6 \%)$. (Table 2$)$.

Table (2): Ground glass distribution.

\begin{tabular}{lcl}
\hline Percent & $\begin{array}{c}\text { Number } \\
\text { of cases }\end{array}$ & \multicolumn{1}{c}{$\begin{array}{c}\text { Predominant } \\
\text { distribution }\end{array}$} \\
\hline $80 \%$ & 40 & lower lobe predominance \\
$6 \%$ & 3 & Upper lobe predominance \\
$14 \%$ & 7 & Equal distribution in upper and lower lobe \\
$92 \%$ & 46 & Peripheral distribution \\
$6 \%$ & 3 & Peripheral and perihilar distribution \\
\hline
\end{tabular}

The faint ground-glass opacities were mostly peripheral in $46(92 \%)$ of the patients, whereas 3 individuals $(6 \%)$ had both peripheral and peri-hilar distribution (Table 2).

Consolidation was only seen in three patients $(6 \%)$ of the time.

\section{Discussion}

COVID-19 is a highly contagious sickness caused by the severe acute respiratory syndrome coronavirus 2 (SARS-CoV-2) [6].

There are currently no antiviral medicines or other particular therapy that have been validated for the treatment of COVID-19. The condition is only treated symptomatically; what's more important is to keep the disease from spreading, which is referred to as "flattening the curve" in epidemiology [7].
As a result, early diagnosis of COVID-19 patients (radiologic or otherwise) is crucial for isolating these cases and preventing further infection [8].

CT is a significant and widely used tool for diagnosing and assessing the severity of COVID19 , as well as monitoring disease development and assessing therapy efficacy [9].

Quantitative imaging analysis (QIA), which uses Hounsfield units (HU) to precisely identify lung tissue density, can help distinguish otherwise subtle radiographic findings (Fig. 2) [10]

The time between the beginning of symptoms and the first chest CT scan was approximately 68 days. The most common first symptoms were fever in 38 patients (76 percent), dry cough in 28 patients (56 percent), and dyspnea in 15 patients (30 percent), which corresponds with Dong Sun, et al study's [11]

In this investigation, we found that groundglass opacity (GGO) is the most common CT finding in patients with mild/early COVID-19, which was seen in 50 patients $(100 \%)$ and was essentially associated with the disease's course and severity, which coincides with the findings of Feng $\mathrm{Z}$, et al., [12]

GGO identification and recognition is reliant on a subjective judgement of lung attenuation on CT; consequently, CT should be done within objective constraints that ensure reliable and repeatable lesion depiction (Fig. 3) [13]

GGOs aren't always visible on CT scans, and they can go undetected. GGO is diagnosed through a subjective assessment of lung attenuation on CT (Fig. 4) [14]

Ground glass opacity was recognised by both visual and colour coded imaging in 50 patients $(100 \%)$ in this investigation; however, several GGOs were very faint and were only visualised by colour coded pictures and verified by CT density assessment (Fig. 5).

Consolidation was only seen in three patients $(6 \%)$ of the time. This is in line with the findings of Feng $\mathrm{Z}$ et al., [12]

At the initial examination, the lesions ranged in size from $1 \mathrm{~cm}$ to $3 \mathrm{~cm}$ in diameter, which is consistent with a research by Dong Sun, et al., that found a link between the size of the lesion and the severity of symptoms [11]. 
Early detection of patients and assessment of COVID-19 severity may help clinicians choose the best treatment choices and prevent death. The use of both visual and colour coded images assisted

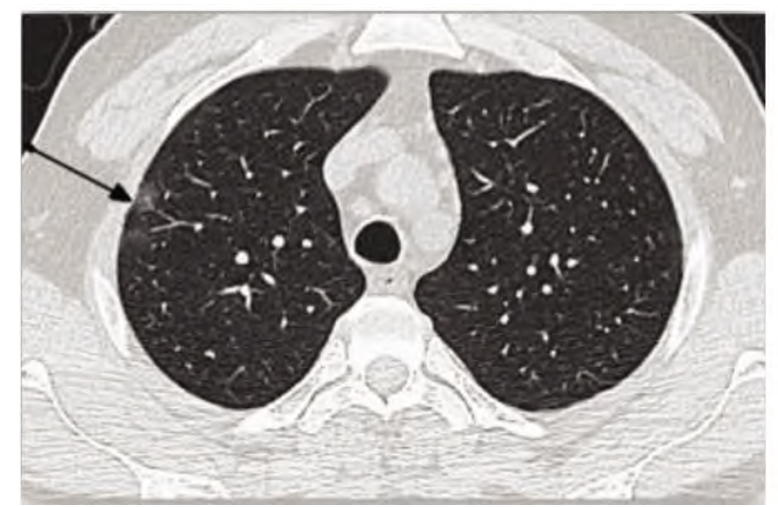

in the diagnosis of mild/early instances of COVID19 in the current investigation, and this was corroborated by a study done by Dong Sun, et al., (Fig. 6) [11]

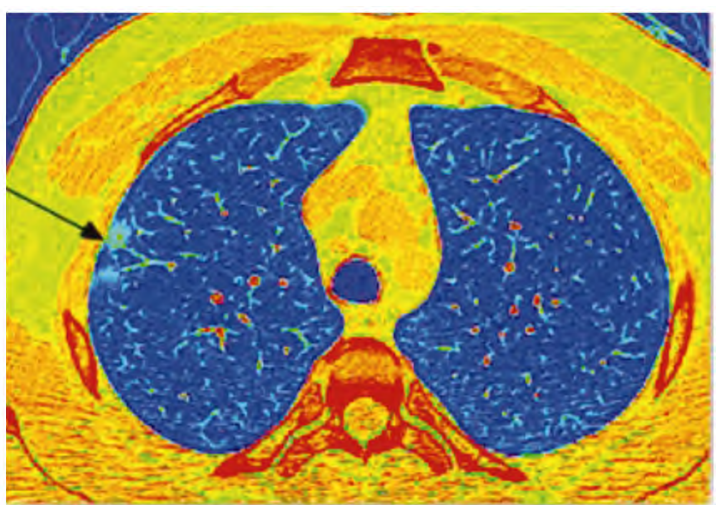

Fig. (2): A female patient 46 years old, presented with chest pain and COVID-19 positive PCR. MDCT was done with color coded images, MDCT showed right upper lobe tiny ground glass pulmonary nodular opacity which was confirmed in color coded image (as a green nodule whose $\mathrm{HU}$ more than $-750 \mathrm{HU}$ and normal lung appear blue color -750 to $-950 \mathrm{HU}$ ).
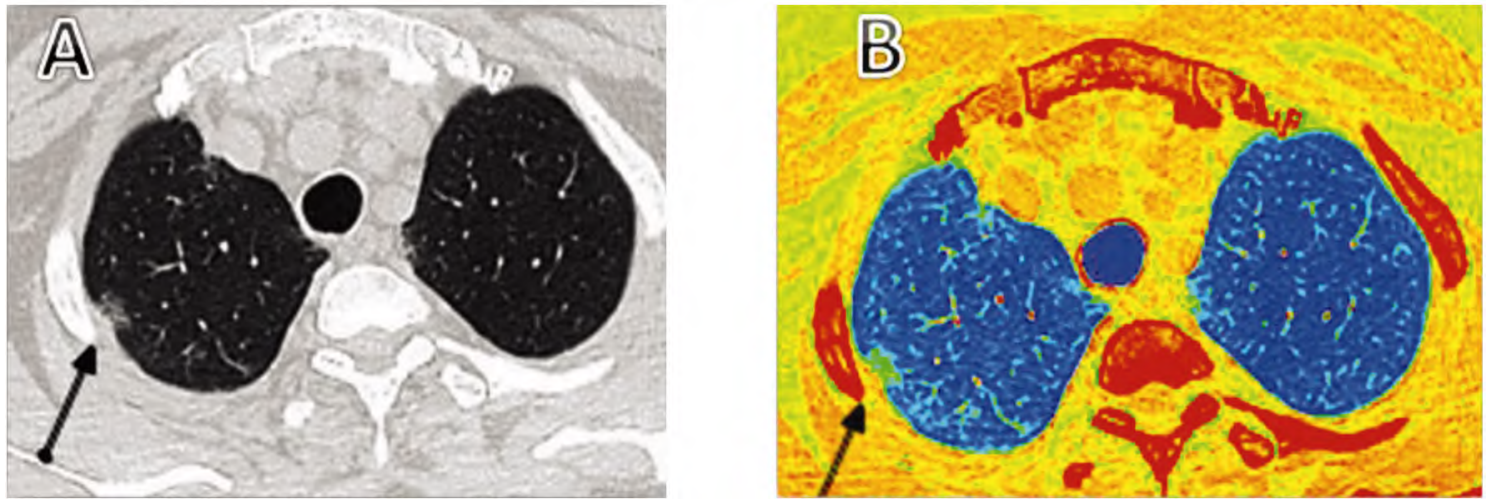

Fig. (3): 60 years old male patient presented with fever \& respiratory symptoms including dry cough, yet CT chest was unremarkable (A) Except for right upper lobe apical segment subpleural ill-defined faint small ground glass opacity, Which became more obvious in color coded images (B) (Green in color).
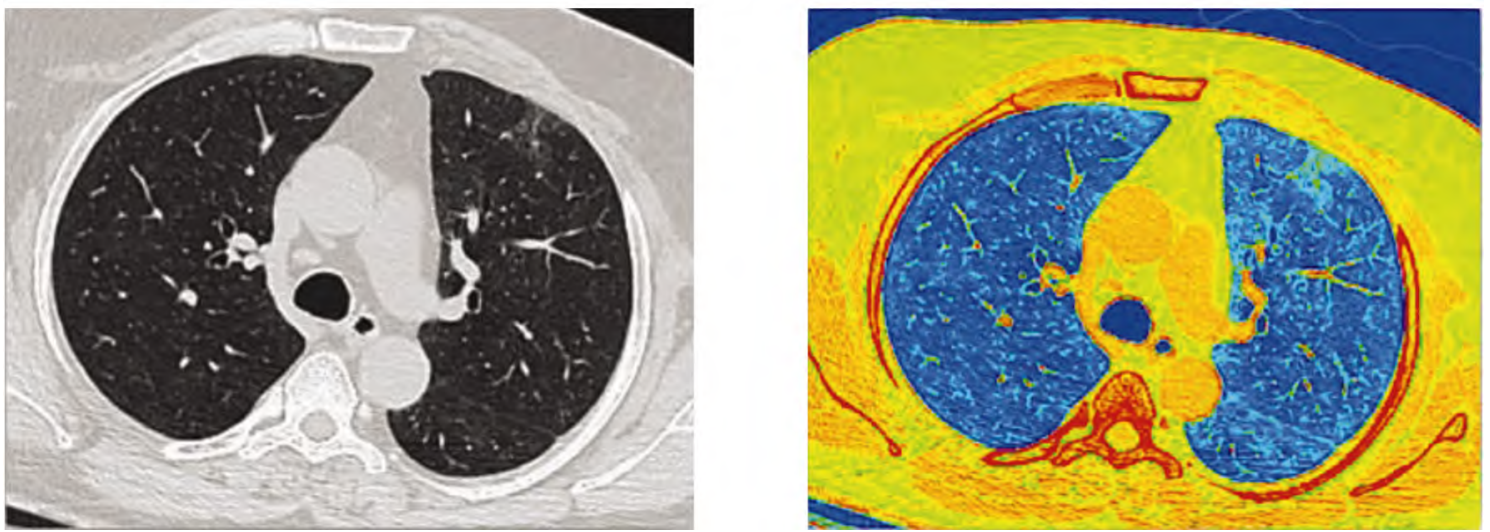

Fig. (4): 32 years old male patient who had mild fever, with positive PCR. MDCT was done showing left upper lobar anterior segment suspected faint subpleural opacity, which was much prominent in color coded images (as small green patch). 

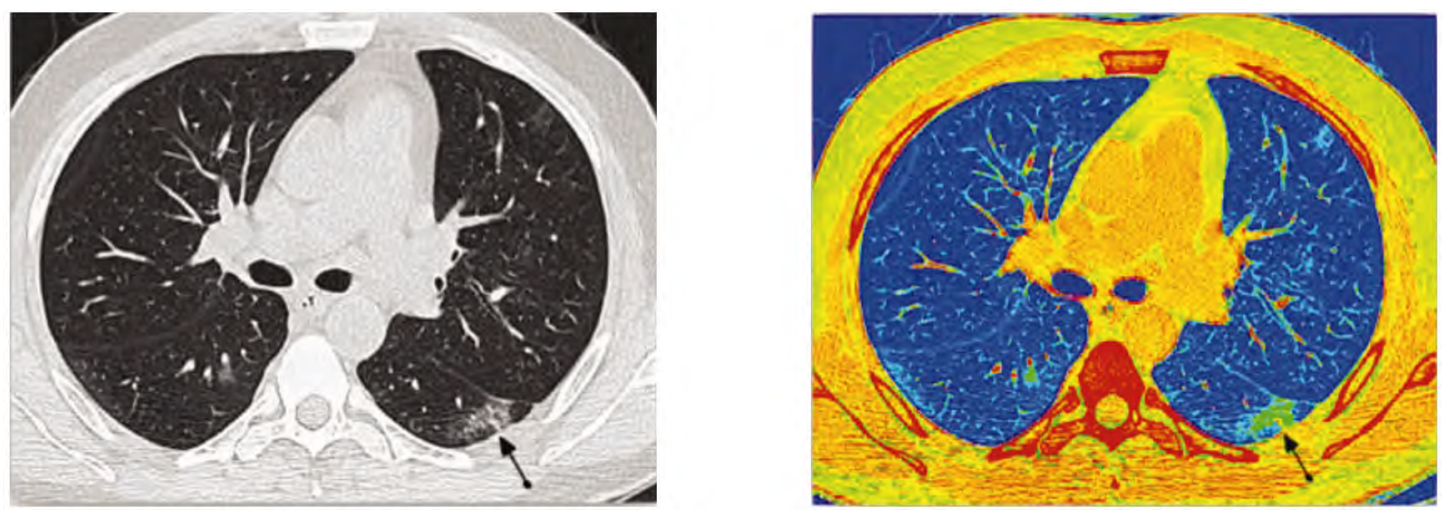

Fig. (5): 25 years old female patient with high grade fever and cough. MDCT was done showing left lower lobe apical segment subpleural patchy area of ground glass opacity. On doing additional color coded images two additional small nodular opacities became clearer in the right lower lobe apical segment and left upper lobe.
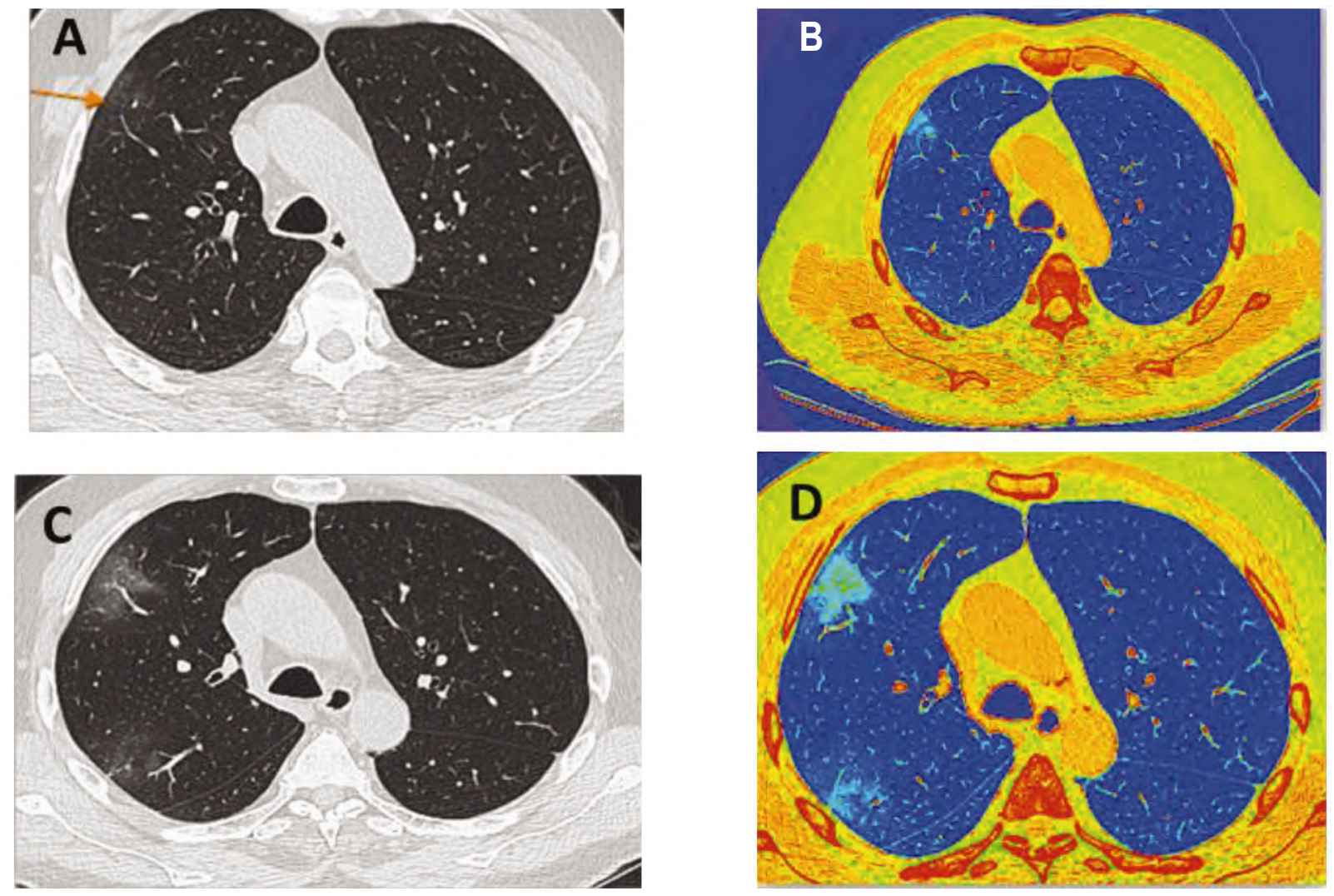

Fig. (6): A male patient 45 years old, presented with dull aching chest pain and dyspnea with PCR positive tests. First MDCT (image A) was done, showing suspected faint ground glass opacity, additional color coded images (B) Showed a right upper lobar apical segment area of abnormal green color (HU more than -750). Follow-up CT done after 8 days (C\&D) showed bilateral scattered mainly peripheral ground glass opacities.

In conclusion, our study found that combining visual and colour coded pictures improves and enhances the early detection of mild ground glass opacities seen in early COVID-19 affection, potentially improving illness prognosis and decreasing the transmission of this highly contagious disease.

\section{Conclusion:}

Although CT represents a fundamental diagnostic tool because of its sensitivity, it still needs to be integrated with clinical data to achieve the best clinical management, early detection of COVID19 is of great value because it may guide clinical treatment options and reduce the mortality rate. In the absence of specific therapeutic drugs and trials of effective vaccines for (COVID-19), GGO diagnosis remains a diagnostic challenge.

The use of both visual and colour coded pictures improves and enhances early detection of subtle 
ground glass opacities seen in early COVID-19 affection, potentially improving disease prognosis and decreasing the transmission of this extremely contagious disease.

\section{References}

1- CHUNG M., BERNHEIM A., MEI X., et al.: CT Imaging Features of 2019 Novel Coronavirus (2019-nCoV) Radiology, 195: 1. [Google Scholar], 2020.

2- BERNHEIM A., MEI X., HUANG M., et al.: Chest CT findings in coronavirus disease-19 (COVID-19): Relationship to duration of infection 10.1148/radiol. 2020200463 [PMC free article] [PubMed], 2020.

3- AI T., YANG Z., HOU H., et al.: Correlation of chest CT and RT-PCR testing in coronavirus disease 2019 (COVID19) in China: A report of 1014 cases. Radiology, 195: 2. [PMC free article] [PubMed] [Google Scholar], 2020.

4- XIE X., ZHONG Z., ZHAO W., et al.: Chest CT for typical 2019-nCoV pneumonia: Relationship to negative RT-PCR testing Radiology 296(2):E41-E45 [PMC free article] [PubMed], 2020.

5- KAUCZOR H.U., HEITMANN K., HEUSSEL C.P., MARWEDE D., UTHMANN T. and THELEN M.: Automatic detection and quantification of ground-glass opacities on high-resolution CT using multiple neural networks: comparison with a density mask. AJR Am. J. Roentgenol., 175 (5): 1329-1334. doi: 10.2214/ajr.175.5.1751329. [PubMed] [CrossRef] [Google Scholar], 2000.

6- WANG D., HU B., HU C., ZHU F., LIU X., ZHANG J., et al.: Clinical characteristics of 138 hospitalized patients with 2019 novel coronavirus-infected pneumonia in $\mathrm{Wu}$ han, China. JAMA, 323: 1061-1069. doi: 10.1001/jama. 2020.1585. [PMC free article] [PubMed] [CrossRef] [Google Scholar], 2020.

7- SIMPSON S., KAY F., ABBARA S., BHALLA S., CHUNG J., CHUNG M., et al.: Radiological society of north america expert consensus statement on reporting chest CT findings related to COVID-19 Soc Thoracic
Radiol. Am. Coll. Radiol. RSNA Radiol., 35 (4): 219227 [PMC free article] [PubMed], 2020.

8- KAKODKAR P., KAKA N. and BAIG M.N.: A comprehensive literature review on the clinical presentation, and management of the pandemic coronavirus disease 2019 (COVID-19) Cureus, 12 (4): e7560. doi: 10.7759/cureus. 7560. [PMC free article] [PubMed] [CrossRef] [Google Scholar], 2020.

9- MAHASE E.: China coronavirus: WHO declares international emergency as death toll exceeds 200. BMJ. doi: 10.1136/bmj.m408. [PubMed] [CrossRef] [Google Scholar], 2020.

10- KIM S.S., SEO J.B., KIM N., et al.: Improved correlation between CT emphysema quantification and pulmonary function test by density correction of volumetric CT data based on air and aortic density. Eur. J. Radiol., 83: 5763. doi: 10.1016/j.ejrad.2012.02.021. [PubMed] [CrossRef] [Google Scholar], 2014.

11- SUN D., LI X., GUO D., et al.: CT Quantitative analysis and its relationship with clinical features for assessing the severity of patients with COVID-19. Korean J. Radiol., 21 (7): 859-868. doi: 10.3348/kjr.2020.0293. [PMC free article] [PubMed] [CrossRef] [Google Scholar], 2020.

12- FENG Z., YU Q., YAO S., LUO L., DUAN J., YAN Z., et al.: Early prediction of disease progression in 2019 novel coronavirus pneumonia patients outside Wuhan with CT and clinical characteristics. Med. Rxiv., [Accessed 23 Feb 2020]. Available at: https://www.medrxiv.org/ content/10.1101/2020.02.19.20025296v1. [Google Scholar], 2020.

13- NAMBU A., ARAKI T., TAGUCHI Y., et al.: Focal area of ground-glass opacity and ground-glass opacity predominance on thin-section CT: discrimination between neoplastic and non-neoplastic lesions. Clin. Radiol., 60: 10061017 (CrossRefPubMedWeb of Science Google Scholar) [PubMed], 2005.

14- TERRY S.F.: Obama's precision medicine initiative. Genet Test Mol Biomarkers, 19 (3): 113-114. doi: 10.1089/gtmb 2015.1563. [PMC free article] [PubMed] [CrossRef] [Google Scholar], 2015.

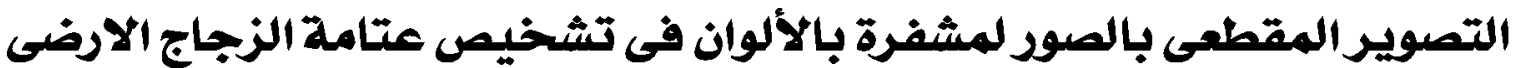

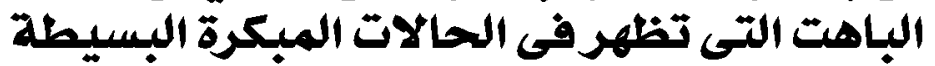

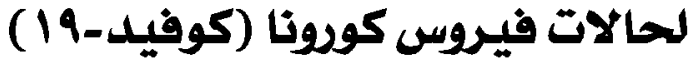

$$
\begin{aligned}
& \text { الخلفية: الأشعة المقطعية على المدر هو وسيلة تثخيص أساسية ويسيطة الكشف المبكر عن التفيرات الرئوية فى المرضى كوفيد-19. } \\
& \text { تقنية شبه كمية اعتماداً على كل من الصقد البصرية واللون مرمزة يساعد على تصسين الكثف المبكر لمرضى كوفيد-19 وبالتالى تساعد } \\
& \text { على السيطرة على انتشار العدوى. }
\end{aligned}
$$

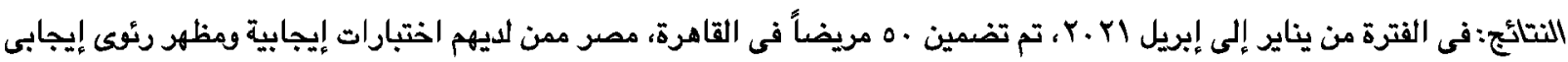

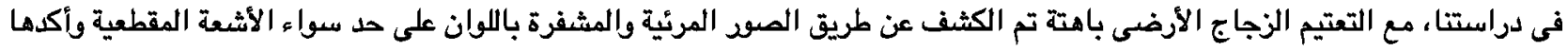
تقييم كثافة.

الاستتاجات: الاستخدام المشترك للصوف المرئية والمشفرة بالألوان يعزن ويحسن الكشف المبكر عن التعتيم الزجاجى الأرضى الخافت 